\title{
Mycosis Fungoides Variant
}

National Cancer Institute

\section{Source}

National Cancer Institute. Mycosis Fungoides Variant. NCI Thesaurus. Code C39644.

A header term that includes the rare following variants of mycosis fungoides:

folliculotropic mycosis fungoides, granulomatous slack skin disease, and pagetoid

reticulosis. 